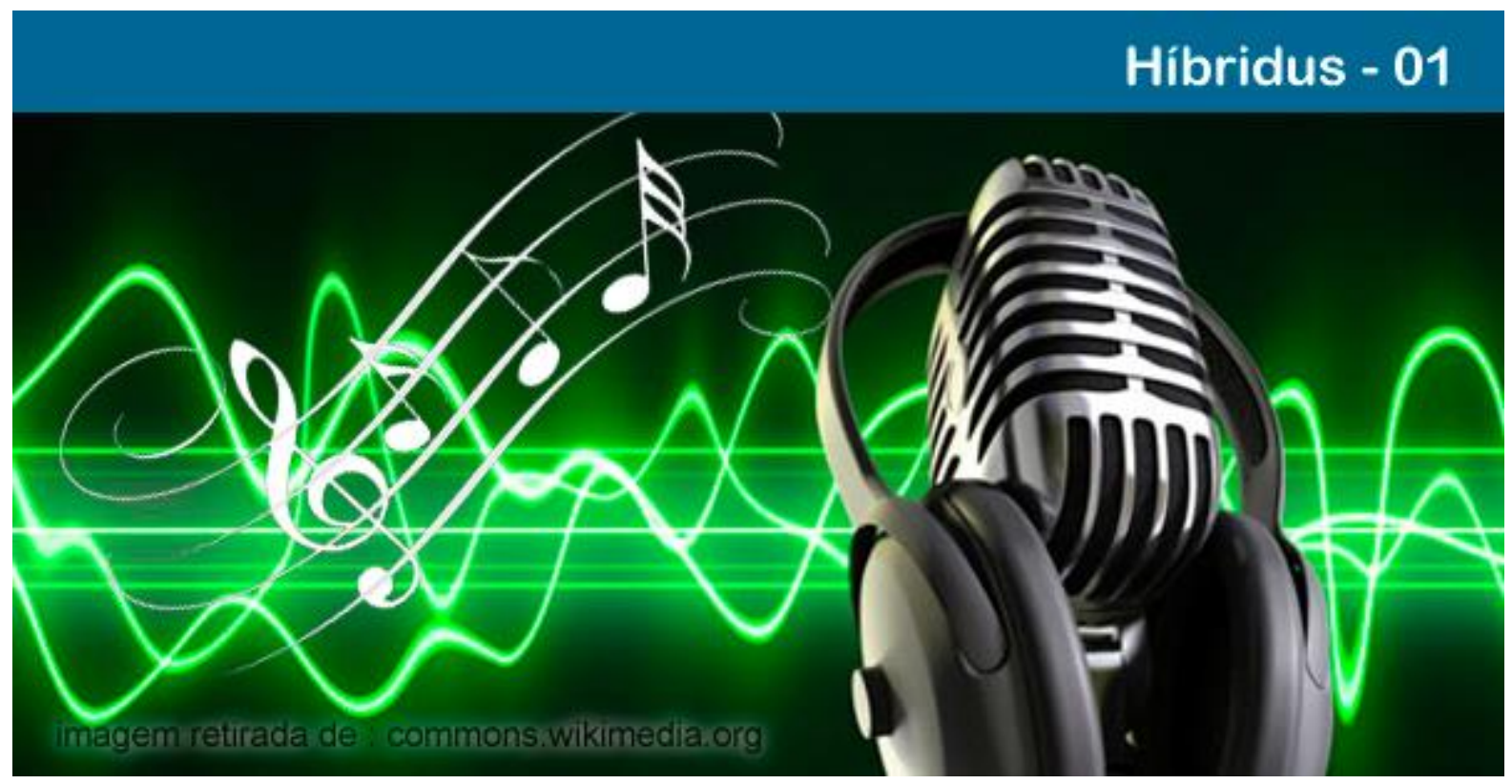

\title{
RADIOARTE NA WEB E NO RÁDIO ${ }^{1}$
}

\section{Mauro José Sá Rego Costa}

Doutor em Educação pela Universidade Federal do Rio de Janeiro (UFRJ). Professor Aposentado da Universidade do Estado do Rio de Janeiro (UERJ). Líder do grupo de pesquisas Kaxinawá Pesquisas Sonoras CNPq. E-mail: maurosarego@gmail.com.

\section{Marcelo Wasem}

Músico. Doutor em Artes Visuais EBA/UFRJ. Professor Adjunto do Instituto de Artes - IA - UERJ. Membro do grupo de pesquisas Kaxinawá Pesquisas Sonoras-CNPq.

\section{Mariana Novaes}

Mestre em Artes Visuais pelo PPGAV/UFRJ. Doutoranda em Arte, Cognição e Cultura pelo Programa de PPGARTES/UERJ.

Resumo: Um pequeno panorama da História e da situação atual da audição de peças de rádio arte em emissoras de rádio FM-AM e em webradios no mundo e, em especial, no Brasil. Trata com maior detalhe da criação da rederadioarte, uma rede criada na web para intercambio entre radioartistas do Brasil e alguns de fora, e sua proposta, já em execução, de produção de programas para rádios educativas brasileiras.

Palavras-chave: Radioarte. Webradio. Rederadioarte. Rádios educativas.

\section{RADIO ART ON THE WEB AND ON THE RADIO}

Abstract: A short overview of the history and current situation of listening radio art pieces in FM-AM radio stations as well as in webradios worldwide and specially in Brazil. Comes in more detail with the creation of rederadioarte, a network on the web for the communication among Brazilian and some foreign radioartists; and its proposal, already active, of broadcasting radio art programs in Brazilian educational radios.

\footnotetext{
${ }^{1}$ Trabalho apresentado no Grupo de Trabalho de Rádio e Meios Sonoros no $9^{\circ}$ SOPCOM - Congresso da Associação Portuguesa de Ciências da Comunicação, Coimbra, 2015.
}

\section{POLÊM!CA LABORE (}

Polêmica - Revista Eletrônica da Uerj - Rua São Francisco Xavier, 524, $1^{\circ}$ andar

bloco D, sl.1001 • Tels.: +55 21 2334-4088/4087 • http://www.e-publicacoes.uerj.br/index.php/polemica/index http://www.labore.uerj.br • laboreuerj@yahoo.com.br 
Keywords: Radio art. Webradio. Rederadioarte. Educational radio stations.

Apesar da radioarte ter surgido junto com o próprio rádio, nas experiências do Hörspiel alemão, a partir de 1923 (HAOULI, 2002), hoje radioarte é praticamente uma especialidade de algumas dezenas de webradios em todo o mundo. As exceções, fora da web, são poucas rádios culturais públicas como a WDR de Colônia ou a RadioAtelier de Helsinque que chegam a patrocinar a produção de programas por radiomakers de todo o mundo, a France Culture ou Radio Educación (México).

No Brasil, experiências com radioarte só surgem na década de 1970 com a realização de seminários e concursos de peças radiofônicas numa colaboração entre o Instituto Goethe, a Fundação Konrad Adenauer e o Grupo Opinião (Teatro). A partir desta iniciativa, jovens dramaturgos como Fernando Peixoto, Germano Blum e João das Neves foram convidados a estudar o gênero Horspiel na WDR, em Colônia. Em 1985, novamente, a WDR, associada à Fundação Padre Anchieta - Rádio Cultura FM, de São Paulo - promoveu um concurso de peças radiofônicas, cujo prêmio incluía um estágio na emissora alemã (HAOULI, 2007).

Obras originais neste gênero ainda vão esperar até as primeiras produções de Janete El Haouli: Stratosound (1997) - um retrato acústico do pesquisador e performer da voz egípciogrego-italiano Demetrio Stratos - e Brasil Universo em parceria com o músico brasileiro Hermeto Pascoal (1999) - ambas em coprodução com a WDR de Colônia, que também as transmitiu. Da mesma forma, Regina Porto, que foi comissionada, em 2002, para fazer a peça Metrópole - São Paulo, um retrato acústico da cidade de São Paulo, para a WDR.

Mas rádio-arte e artes sonoras vão aparecer no Brasil, em eventos artísticos mais amplos, apenas na $7^{a}$ Bienal do Mercosul, em 2009, com a página de rádio em streaming Radiovisual: excitadora de frequências, criada e coordenada pela artista Lenora de Barros. E depois, na 30 a Bienal Internacional de São Paulo (ago./dez., 2012) com a Mobile Radio BSP, produzida por Sarah Washington e Knut Aufermann da mobile-radio.net - http://mobileradio.net/. A Mobile Radio $B S P^{2}$ transmitiu 24hs por dia, de 3 de setembro a 9 de dezembro de 2012, do Pavilhão do Ibirapuera para o mundo, via web, e numa emissora FM de baixíssima potência que só chegava até os limites do Parque do Ibirapuera, onde está o Pavilhão da Bienal.

${ }^{2}$ Ver em http://mobile-radio.net/?page_id=1715.

\section{POLÊM!CA $\mid$ LABORE}

Polêmica - Revista Eletrônica da Uerj - Rua São Francisco Xavier, 524, $1^{\circ}$ andar

bloco D, sl.1001 • Tels.: +55 21 2334-4088/4087 • http://www.e-publicacoes.uerj.br/index.php/polemica/index

http://www.labore.uerj.br • laboreuerj@yahoo.com.br 
Sarah e Knut e seu mobile-radio.net são atualmente os principais ativistas para o desenvolvimento da radioarte no mundo. Em 2006, 2008 e 2010, organizaram três Bienais de Radio Arte na Radio Zero de Lisboa, o RadiaLx, aliás, os únicos períodos em que a Rádio Zero chegou a transmitir em FM, além da sua usual webradio. Organizaram vários outros Festivais introduzindo ou estimulando a RadioArte em lugares como Talinn, na Estônia (2011); Halle, na Alemanha (2006) e Estocolmo, na Suécia (2013).

Entre os artistas que mais estimularam o desenvolvimento da radioarte no Brasil é importante citar a produtora musical, radioartista e também curadora, Lilian Zaremba, que vem produzindo programas com música experimental e artes sonoras há 17 anos na Rádio MEC FM, do Rio de Janeiro. Além de grande produção em instalações sonoras - gênero que mistura as instalações das artes plásticas com as artes sonoras -, Lilian também foi responsável por vários encontros e simpósios tratando da radioarte e das artes sonoras, desde o primeiro Radioforum no Centro Cultural Banco do Brasil (Rio de Janeiro), em outubro de 1997 - com as comunicações de pesquisadores e radioartistas brasileiros e estrangeiros publicadas em uma edição da coletânea Rádio Nova. Constelações da Radiofonia Contemporânea (ZAREMBA, BENTES, 1999). Organizou também o evento O que eu faço é rádio, em 2006, no Museu de Arte Contemporânea de Niterói, com mesas redondas e mostras de produção radioartística; e o Entreouvidos, sobre rádio e arte, na Escola de Artes Visuais, Rio de Janeiro, em 2007 (ZAREMBA, 2009).

O evento Mobile Radio BSP foi, no entanto, o gatilho para o desenvolvimento mais recente e importante da radioarte brasileira, ao permitir o encontro e conhecimento mútuo de inúmeros artistas sonoros e radioartistas cuja audiência - em função da falta de veículos de distribuição mais ampla - estava restrita aos seus círculos mais próximos.

Assim, puderam se aproximar e trocar experiências artistas como Renata Roman, que com seu Atelier Sonoro ${ }^{3}$ fez, um programa semanal na Radio BSP, Paisagens \& Poéticas, em que selecionava um poeta de um bairro de São Paulo e mixava sua participação à paisagem sonora do mesmo bairro - utilizando seu grande projeto de mapeamento sonoro da cidade; Marssares, cujo trabalho é definido por Lilian Zaremba como uma junção entre a música, os mixes, os mashups dos DJ's e a arte sonora e já se apresentara, entre outros eventos, na $52^{\mathrm{a}}$ Bienal de Veneza, em junho de 2007; Alex Hamburguer, que trabalha desde os anos 1980

${ }^{3}$ Ver em http://ateliesonoro.blogspot.com.br/.

\section{POLÊM!CA $\mid$ LABORE}

Polêmica - Revista Eletrônica da Uerj - Rua São Francisco Xavier, 524, $1^{\circ}$ andar

bloco D, sl.1001 • Tels.: +55 21 2334-4088/4087• http://www.e-publicacoes.uerj.br/index.php/polemica/index http://www.labore.uerj.br • laboreuerj@yahoo.com.br 
com poesia visual e sonora, com participações diversas e singulares nos programas radiocaos transmitidos pela Rádio Roquete Pinto (Rio de Janeiro), Rádio USP (São Paulo) e Rádio EParaná (Curitiba), e que criou cerca de 30 trabalhos em performances, publicou 5 livros de 'poesia verbal' e 2 CDs de 'poesia sonora' - parte do acervo da Printed Matter Bookstore New York, e do Compendium of Contemporary Fine Prints - Hamburgo, Alemanha ${ }^{4}$; Thelmo Cristovam, de Olinda, Pernambuco, que tem uma produção singular de uma geografia sonora do estado de Pernambuco - paisagens sonoras da Ilha de Fernando de Noronha, do Vale do Catimbau, do Mercado de S. José (Recife), das ruas e do tráfego urbano de Recife e Olinda, como também dos arredores do Lago Mamori no Amazonas. Thelmo tem também um trabalho precioso de Oficinas de experiência com paisagens sonoras ao vivo com jovens das comunidades populares de Olinda e Recife - Ambientes Sonoros Imersivos ${ }^{5}$. E, finalmente, o grupo paulista $A l$ Revés, que fazia programas quinzenais de música eletrônica experimental, na RBSP. O grupo se autodefine como "um projeto musical que promove e desenvolve pesquisas e trabalhos livres de contornos de estilo, moda ou mercado. Seu objetivo é reunir materiais que beirem os limites da criação musical (...)" ${ }^{\text {"6 }}$ Apontam como seus apoiadores o selo francês Bedroom Research; o Psicotropodelia, cujo último álbum - "Psicotropodelia Music Vol.5" - tem três horas de faixas com artistas do Brasil, Bélgica, Austrália, Rússia, Espanha, França, Alemanha, Reino Unido e Uruguai ; além dos Decisive Sound Records, Frozen Elephants e Okiru. O Al Revés lança discos através de seu selo digital Al Revés, para download gratuito, sob licença Creative Commons ${ }^{8}$.

O encontro com estes artistas estimulou nosso grupo de pesquisas sonoras da Universidade do Estado do Rio de Janeiro - o Kaxinawá Pesquisas Sonoras ${ }^{9}$ - a dar os passos iniciais para a criação de uma plataforma na web dedicada exclusivamente à radioarte - a RedeRadioArte (http://rederadioarte.com/). E a partir da criação da rede, ainda ampliamos nossos contatos com outros produtores de radioarte no Brasil e alguns de fora do Brasil.

\footnotetext{
${ }^{4}$ Ver em http://www.radiocaos.com.br/website/?p=1328; http://radioforumbr.com/poesiasonora/; http://poeticasexperimentaisdavoz.wordpress.com/2007/09/01/4/.

${ }^{5}$ Ver em https://www.youtube.com/user/ThelmoEscuta/videos.

${ }^{6}$ Ver em http://alreves.org/about.php?lang=br.

${ }^{7}$ Ver em http://www.psicotropicodelia.com/.

8 Ver em http://www.alreves.org/.

${ }^{9}$ O Kaxinawá Pesquisas Sonoras, formado em 2012, é composto por pesquisadores universitários, igualmente artistas sonoros, da Faculdade de Educação da Baixada Fluminense (FEBF) e Instituto de Artes da UERJ; e do IAD - Instituto de Artes e Design - da Universidade Federal de Juiz de Fora .
}

\section{POLÊM!CA $\mid$ LABORE}


Assim chegam Diogo Reis, DJ e produtor de uma singular festa de música eletrônica, techno, mix no Rio de Janeiro - a $\mathrm{Moo}^{10}$ - , marcante pelo cuidado técnico sonoro e de design, trazendo o universo do entretenimento, das baladas, para o espaço da Arte - e que reúne em torno de si uma turma especial de músicos experimentais e DJ's criadores; Marcelo Villena, compositor argentino radicado no Brasil, professor da Universidad Federal de la Integración Latinoamericana (UNILA), que trabalha com paisagens sonoras, música electroacústica e instalações sonoras e também orienta um grupo de pesquisas sonoras na Universidade; Anja Mauruschat, professora da Universidade de Basel na Suíça, que trabalhou por dez anos em rádios públicas, com programas sobre literatura e artes antes de seguir a carreira acadêmica - atualmente, está fazendo seu doutorado investigando o conceito de "radio arte absoluta", como o trataram desde os anos 1920, artistas como Kurt Weill, Walter Ruttmann, John Cage, Mauricio Kagel e outros (ver seu blog Eletronic Arts. New Ways of Thinking ${ }^{11}$ ); GRISom, o grupo de investigações em linguagens sonoras da Faculdade de Filosofia e Ciências Humanas da Universidade Federal de Minas Gerais (UFMG), através de sua coordenadora, professora do Departamento de Comunicação, Graziela Mello Vianna ${ }^{12}$. Também o grupo português OSSO - OSSO Associação Cultural - e seu projeto de rádio ECOS, de Nuno Torres, Ricardo Jacinto e Sara Morais ${ }^{13}$. E, finalmente, o QUINTAVANT, um grupo de produtores que programa eventos que acontecem no Estúdio Audio Rebel, em Botafogo, Rio de Janeiro, criado sob a inspiração de casas dedicadas à improvisação coletiva e à experimentação, tais como o Plano B (Lapa - RJ) e The Stone (Nova Iorque). QUINTAVANT é produzido por Pedro Azevedo (responsável pela Audio Rebel), Renato Godoy (baterista do Chinese Cookie Poets e técnico de som e gravação), Alex Zhemchuzhnikov (saxofonista do Sobre a Máquina e produtor) e Bernardo Oliveira (crítico de música no blog Matéria) ${ }^{14}$.

O projeto da rede foi desde o início permitir o conhecimento mútuo e o intercâmbio entre os artistas e produtores nessa área, além da possibilidade de produção coletiva de programas de rádio para transmissão em web radio da própria plataforma e nas rádios educativas universitárias em frequências FM e AM. Nossa perspectiva é que a ampliação do

\footnotetext{
${ }^{10}$ Ver em https://www.facebook.com/MOO.Eventos; http://cargocollective.com/moo-historico

${ }^{11}$ Ver em http://aniamauruschat.de/.

${ }^{12}$ Ver em http://www2.fafich.ufmg.br/gris/index.php/nucleos-de-pesquisa/linguagens-sonoras.

${ }^{13}$ Ver em http://osso.pt.

${ }^{14}$ Ver em https://www.facebook.com/quintavant.
}

\section{POLÊM!CA $\mid$ LABORE}


número de ouvintes de radioarte tem um caráter educacional - de "educação da escuta" - no mesmo viés da proposta de Murray Schafer em relação às "paisagens sonoras" - aliás, conteúdo bastante frequente nas peças de radioarte. O outro aspecto que sublinhamos é o da inclusão da radioarte no espectro das artes contemporâneas, proposta já incorporada em mostras internacionais de arte como a Bienal de Veneza e a Documenta de Kassel, e que inspirou o convite a Sarah Washington e Knut Aufermann para a Bienal de São Paulo de 2012. Nesta direção, estamos em negociação com a direção do Museu de Arte Contemporânea de Niterói para a criação de uma web radio exclusiva de radioarte no site do Museu.

Em relação à inclusão de programas de rádio arte nas rádios educativas, já conseguimos através da RedeRádioArte, desde o início de setembro, a transmissão de um programa semanal, aos sábados à tarde - horário nobre - na Rádio UFMG Educativa, da Universidade Federal de Minas Gerais, em Belo Horizonte. Os mesmos programas são transmitidos, a partir de janeiro de 2016, na Rádio MEC FM do Rio de Janeiro, nas segundasfeiras, à meia-noite.

Para concluir, Sarah Washington e Knut Aufermann, através de seu mobile-radio.net tiveram uma iniciativa marcante em 2005, fomentando a criação de uma rede internacional informal de rádio que transmite radio arte: a radia.fm. Hoje, já independente do mobileradio.net com seu próprio site - http://www.radia.fm/ - a radia.fm já reúne 26 estações comunitárias, livres e webradios em 23 cidades de 16 países, falando 10 línguas diferentes. Para dar alguns exemplos: a CFRC 101.9 FM de Kingston e a CKUT de Montréal, no Canadá; a Eastside FM em Sydney, Austrália; a Campus Paris, de Paris, a JET FM de Nantes e a Radio Grenouille de Marselha, na França; a Kanal 103, de Skopje, na Macedônia; a Orange 94.0 e a Kunstradio, ambas de Viena, e a Radio Helsinki, de Graz, na Áustria; a $\underline{\text { Radio Campus, a XL Air e a Radio Panik de Bruxelas, Bélgica; a Radio Corax }}$

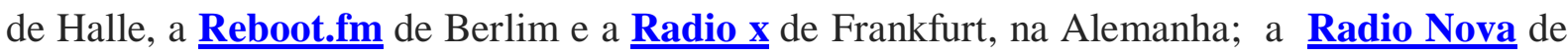
Oslo, Noruega; a Radio One 91 FM de Dunedin, Nova Zelândia; a Radio Papesse de Florença, Itália; a Radio Student de Ljubljana, na Eslovênia; a Rádio Zero de Lisboa, Portugal; a RadioWORM de Roterdam, Holanda; a Resonance104.4fm de Londres, e a

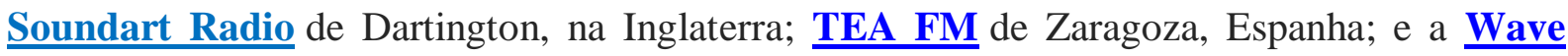
Farm WGXC 90.7-FM de New York, Estados Unidos.

\section{POLÊM!CA $\mid$ LABORE}




\section{Referências}

HAOULI, Janete El. "Mordendo a própria cauda: peça radiofônica alemã e experimentação de vanguarda". In: BALOGH, Anna Maria; ADAMI, Antonio; DROGUETT, Juan; CARDOSO, Haydèe Dourado de Faria (Org.). Mídia, Cultura, Comunicação. São Paulo, Editora Arte \& Ciência, 2002. São Paulo, 2002. p. 167-180.

Radio arte no Brasil 1. 2007. Disponível em:

<http://www.guiadamusica.org/conteudo/reflexoes/reflexoes.php?id_reflexao=3>. Acesso em: 13 mai. 2016.

ZAREMBA, Lilian; BENTES, Ivana. Radio Nova. Constelações da Radiofonia Contemporânea. v. 3. Rio de Janeiro: UFRJ, ECO, Publique, 1999.

ZAREMBA, Lilian (org.) Entreouvidos, sobre rádio e arte. Rio de Janeiro: Soarmec Editora, Oi Futuro, 2009.

Recebido em: 09/03/2016.

Aceito em: 13/05/2016.

\section{POLÊM!CA $\mid$ LABORE}

Polêmica - Revista Eletrônica da Uerj - Rua São Francisco Xavier, 524, $1^{\circ}$ andar bloco D, sl.1001 • Tels.: +55 21 2334-4088/4087 • http://www.e-publicacoes.uerj.br/index.php/polemica/index http://www.labore.uerj.br • laboreuerj@yahoo.com.br 